\title{
THE FUNCTIONING OF THE INTERNET MEDIA IN THE RUSSIAN MEDIA SPACE
}

\author{
Ramis R. Gazizov ${ }^{1}$ \\ Tatiana A. Nagovitsyna ${ }^{2}$
}

\begin{abstract}
Internet media occupy a estimation of functional, leading place in the modern media technological, and creative system. This type of media is characterized by a number of advantages: efficiency, economy, usability. On the one hand, they embody the advantages of traditional media, but multimedia and interactive technologies provide new opportunities for information exchange, and audience expansion. The tendencies of the Internet publication Islam-Today.ru ("Islam Today") development, which is the
\end{abstract} federal information and analytical portal opened five years ago and now is one popular and authoritative

\section{Introduction}

religious-oriented news sites of the country, are considered. The

\footnotetext{
${ }^{1}$ Kazan Federal University, Kremliovskay astr, 18, 420008, Kazan, Russian Federation. Email: gazizov-da@yandex.ru. Tel.: (919) 684-00-77.

${ }^{2}$ Kazan Federal University, Kremliovskay astr, 18, 420008, Kazan, Russian Federation. Email: nagovitsinatatyana@mail.ru.. Tel.: (904) 679-56-60.
} 
The study is devoted to the identification of the features on the functioning of modern Internet media in the regional Russian mass media space. The research uses the following concepts: multimedia, interactive, electronic media outlet, media language, and genre.

Multimedia is mean by information that combines text, image, and sound; those technologies allow you to enter, save, process and reproduce not only textual, but also another types of information: audiovisual, graphic, three-dimensional and other information.

Electronic media outlet is a media that distributes textual, visual, audible and other information presented in an electronic medium or in a network version. It is believed that the common for all electronic publications are digital methods of describing information and similar
231

technologies for managing this information when it is presented.

Media language is the language of the mass-media communications, a stable system of linguistic properties and characteristics, and a sign system for the correlation of verbal and audiovisual components specific to each of the media: printed (press), audiovisual (radio, television, the Internet).

The genre is understood as a kind of journalistic work. The authors adhere to the three-stage basis of genre formation in the mass media: information, problemanalytical, artistic-journalistic genres. Taking into account the specifics of Internet publications, special attention is paid to the information group of the journalism genres.

\section{Materials and methods}


The material of this research was the publication of the information and analytical federal portal Islam-Today.ru. The time interval covers the content of the site for 2017.

The methods used were: system analysis, content analysis, and comparison and collation analysis; they allowed the essential features to reveal in the development of this Internet media.

\section{Results}

The results of the research are broken down according to technological, genre and linguistic specifics, which form the basis of the media activity of this publication.

Technological specificity.

The media design of the media outlet is determined, mainly, by the visual attractiveness of its structure. This includes: graphic design, font size and type, color characteristics, as well as the volume and quality of multimedia content.

The study shows that the multimedia and interactive capabilities of the portal under consideration are diverse, contribute to the realization of various functions of the media: direct organizational, promotional and reference, forming the culture of society, and recreational.

\section{Genre specificity.}

The main part of the content of original journalistic texts is of information genres, what is explained by the peculiarities of the functioning of Internet media.

\section{Discussion}

Analysis of the technological component of the media outlet is as follows. The multimedia capabilities of the media outlet under study are as follows: 
information retrieval, the ability to work with various applications (specifically: with text, graphics and audio editors, video). Viewing a slideshow is limited in nature: it is not accompanied by sound, animation, or audio citations.

Technical characteristics of the portal are in the presence of a mobile version: the media structure of the site has been automatically adapted to the user's devices. Corresponding to the basic multimedia characteristics, the resource provides an opportunity to listen or read books [1]. In addition, through innovative functionality, recreational functions are realized (for example, games: doing puzzles, guessing).

Having sufficiently widely use various multimedia features, the portal nevertheless has certain omissions. You should pay attention to such parameters as authorization and multilanguage ability [2]. The main function of authorization is to recognize the visitor, restrict or, on the contrary, enhance the access to certain types of content. In addition, authorization blocks spam.

It was revealed that the interactive techniques used by the Internet portal "Islamtoday" are reduced to three main ones: intraportal communication, informativity, and renewability. Intrs-portal communication is based on the evaluation of intra-portal messaging services, forum and feedback [3]. The following technical forms of organization of interactivity are established: e-mail, guest book, and blogs. It is worth highlighting also another form of interactivity - the module "Ask a question to the mufti".

Analysis of linguistic, stylistic, genre features.

Analysis shows that the main part of the content of original journalistic texts is represented by information genres. The most widely distributed are notes, 
information correspondence, reports, blitz surveys. This feature is a direct consequence of the features of the Internet environment [4].

We see with the example of the activity of the media outlet under study that the principle of supplementing the multimedia environment works: the news material is accompanied by a photo report, a video; has thematic links, gives the audience the opportunity to vote and services for commenting [5].

If to speak about the quality component of media, we note that the news materials are presented by announcements, messages from own correspondents, RSS-streams or so-called "news feeds" organized according to chronological and thematic principles.

The structure of information materials is built on the standard principles of news journalism, in particular, the principle of the socalled "inverted pyramid" (short news reports are information-rich texts) [6]. Headlines of the portal texts perform an accenting function, with the aim of: attracting the attention of users, and matching to technical and technological aspects of optimization of search processes [7].

Specificity of the media language.

As the results of the analysis show, this feature is determined by stable linguostylistic features. They are expressed in the presence of cliched and thematically related phrases, the use of specific textforming elements: "stated", "according to words", "as the source pointed out", "as the interlocutor noted", "as the interlocutor added", and others.

Writing text for the Internet is based on methods of search engine optimization and features of perception. Such text should contain key words or phrases, have the 
information property, and should be clearly structured.

The revealed tendency is the use of so-called "sovietisms", words that often appeared on the pages of the Soviet press: "teamer", "leader", "subbotnik", "best worker", and others [8].

Changes in the economic and political spheres influenced the active use of borrowed words [9]. Mostly they are of English origin. Vocabulary of political and economic subjects was replenished with borrowings (for example: "clearing", "promotion", "leasing", "top manager" and others).

Borrowings from the Old Slavonic language are actively used (their English equivalents, for example, are: "good-naturedness", "tree", "youth", "gold" and others) in the texts of the media under study.

It should be noted also a clear religious line of language media behaviour of Islam - Today.ru
235

portal. Media texts contain citations from the Koran accompanied by Arabic-Persian borrowings.

Note that the language features of the portal are similar to analogous processes in other media, and they are expressed in the combination of elements: oral and written speech, colloquial and book lexicon. The use of such language resources leads to the presence of jargons, incomplete syntactic constructions, and so on.

Analysis of the theoretical and empirical material of the Internet media outlet showed that the negative phenomena in the field of the online media language include an oversupply of borrowings (mainly Anglicisms and Arabisms), jargon and slang, vernaculars, an abundance of "extra words", a lack of communicative culture of communication participants, "blurring" of genre boundaries and more. These disadvantages are due to the informal nature of 
communication and the specifics of this media structure.

\section{Summary}

The nature of the multimedia use in the Islamic media can be called "experimental": the editorial tests new tools and tracks the audience's reaction. Its feature is the availability and variety of media services for visualizing information and submitting it in a multimedia way. These tools are accessible and understandable to users. Among the positive aspects of using multimedia in the media outlets, the following can be identified: the desire of journalists for self-development, increasing competitiveness and universalization, development of multimedia thinking, the desire to work in different genre groups. The complexity of the media outlet activity is as follows: preparation of multimedia material takes more time than in the case of creating an ordinary media. In addition, moving
236

to multimedia requires clear planning; and assumes additional financial costs.

Analysis of the portal shows that the main part of content in original journalistic texts is information genres. The most widely distributed are notes, information correlations, reports, and blitz surveys.

Speaking about the qualitative component of media, we note the following: a) the news material is presented by announcements, messages from own correspondents and RSS-streams ("news feed") organized in chronological and thematic sequence; b) advertising materials are represented by the following types: banner advertising, video advertising, photo catalog, and advertising articles.

The language of the Internet media is not only a means of reflecting reality, but also an active tool for creating a virtual reality, and forming a picture of the world. 
Conditions of the Market Model of

\section{Conclusions}

Further understanding of the portal Islam-Today.ru problematics is possible in the following directions. It's not just about determining the textual specifics, but also the nature of the illustrative material (genre, problem and thematic focus). It is expedient to consider media images of religious, political, and cultural figures.

\section{Acknowledgments}

The work is carried out according to the Russian Government Program of Competitive Growth of Kazan Federal University.

\section{Bibliography}

Mediaindustry.

International

Business Management, 9: 13791382.

Gazizov R.R, Nagovitsyna T.A. Features of manipulative technologies in Russian political discourse (on the example of the Tatarstan republic mass media) //Journal of Organizational Culture, Communications and Conflict. 2016. - Vol.20, Is.Special Issue2. P.14 - 18 .

Margarita G. Bogatkina, Elena S. Doroschuk and Ramis R. Gazizov. Converging Innovations in the Modern Humanitarian Science // The Social Sciences. Volume: $10 \mid$ Issue: 7 | Page No.: 1932-1934. DOI:

m10.3923/sscience.2015.1932.1934

Vasil Z. Garifullin and Ruzil G. Mingalimov, 2015. Functioning of the National Media under 
Vasil Zagitovich Garifullin, Ruzil

Galievich Mingalimov. Tatar journalism transformation vectors // Journal of Language and Literature, ISSN: 2078-0303, Vol. 6. No. 3. Iss.1, August, 2015. Pp. 192-194.

Vasil Zagitovich Garifullin, Linar Rustamovich Zakirov. Functioning of civic/citizen journalism in the media space of the Republic of Tatarstan //The Turkish Online Journal of Design, Art and Communication.

TOJDACNovember 2016

SpecialEdition. Pp.2322-2326.

Nagovicina T.A. New priorities of the innovative model of training journalists / / Theory and methodology of modern journalism education. Problems of diagnosis of knowledge. Collection of scientific and methodical papers and materials. Issue 3. - Kazan: Kazan University, 2011. - P. 23-26
Gazizov R. R. On the issue of moral and ethical regulation of manipulative processes in journalism // Modern communicative space of journalistic science, practice and education: contours and reality of new media. Issue 5: a collection of scientific papers / ed. by V. Z. Garifullina, E. S. Doroschuk. - Kazan: Kazan University, 2014. - Pp. 20 - 27.

Akhatova I. E., Gazizov R. R. The idea of social justice in the texts of mass communication / R. R. Gazizov, // Philological Sciences. Questions of theory and practice. Tambov: The diploma, 2015. - № 12 (54). - Part III. - Pp. 17-19.

Nagovitsina T.A. Legal factors of the genesis of representations on information legal relations in the Internet // Right and education. 2017. -№7. -Pp. 85-89. 
Gazizov R. R. The peculiarity of political discourse in the media: the regional dimension // Media and power: the power of the media? Materials of the International Scientific and Educational Conference (Kazan, February 1617, 2017). - Kazan: The University of Kazan University, 2017. - Pp. 6066 